\title{
Retraction Note: Analysis of the influence of the characteristics of mountain soil and the noise in the tunnel on people: active noise control system
}

\author{
Siwen Zeng ${ }^{1,2}$ \\ Published online: 23 November 2021 \\ (c) Saudi Society for Geosciences 2021
}

Retraction Note: Arabian Journal of Geosciences (2021) 14: 912

https://doi.org/10.1007/s12517-021-07212-1

The Editor-in-Chief and the Publisher have retracted this article because the content of this article is nonsensical. The peer review process was not carried out in accordance with the Publisher's peer review policy. The author has not responded to correspondence regarding this retraction.

The original article can be found online at https://doi.org/10.1007/ s12517-021-07212-1.

Siwen Zeng

zengswhj@sina.com

1 Institute of Construction Management, Huazhong University of Science \& Technology, Wuhan 430074, Hubei, China

2 College of Civil Engineering and Architecture, Nanchang Hangkong University, Nanchang 330063, Jiangxi, China 